\title{
OS IDEAIS NA CULTURA TÉCNICA
}

Jurandir Antonio Xavier

Sem indícios de uma vigorosa retomada do crescimento econômico, mesmo depois de se vivenciar a "década perdida" dos $80 \mathrm{e}$ acumulando ameaças de se varar em estagnação a dos 90 , processa-se atualmente à revisão do ideário econômico-desenvolvimentista, redimensionando-se nele o peso que educação, ciência e tecnologia viriam a ter no desenvolvimento dos paises subdesenvolvidos, a exemplo do Brasil. Nesta revisão, destaca-se o atrelamento unilateral em que o sistema educacional. cientifico e tecnológico teria se submetido: ao chamado "capital morto", ficando às calendas o "capital vivo". Isso significa que tal sistema teria evoluído em torno do aprimoramento da máquina relegando o do homem. Revisão que vem gerando propostas de voltar tal sistema à elevação da qualificação técnica do trabalhador.

Ilustra uma tal revisão, a que o Sr. Delfim Netto fez aparecer em "Políticas Geradoras do Desenvolvimento" (1993):

"Desde o extraordinário artigo de Robert Solow (1956). Prêmio Nobel dc 1987. os economistas conformaram-se a trabalhar com um modelo simples, que atribuía o crescimento a um misterioso fator chamado 'capital'. à quantidade de trabatho homogêneo aplicada sobre ele e a uma entidade mágica chamada 'tecnologia'. Na verdade, a palavra 'tecnologia' era uma forma de capturar tudo aquilo que os economistas desconheciam e que não estava incorporado ao capital físico ou ao trabalho. (...) Apesar do desconforto e do pessimismo de al-

' Professor titular de Economia da UFPB.

Rev. Raizes, Campina Grande, Ano XIII, n 10, pp.153-160, Dez. 1994. 
gumas de suas conclusões, o modelo de Solow não foi perturbado durante 30 anos. A partir de meados dos anos 80, alguns economistas - P.M. Romer (1986) e R. Lucas (1988) - começaram a desenvolver novos modelos que modificavam certas hipóteses de Solow e permitiram algumas conclusões mais otimistas. (...) Romer (1986) introduziu a hipótese de rendimento crescente do capital e Lucas (1988) sugeriu um terceiro fator de produção, a que chamou de 'capital humano'. (...) (Tal sugestão) desenvolve velha intuição de que o desenvolvimento tem profundas ligações com a educação (Selowsky, 1962). Na sua origem, entretanto, a educação está ligada a fatores institucionais e religiosos. (...) (Mas), uma vez posto em marcha o processo, é certo que os dois fatores se reforçam mutuamente."

Delfim Netto fala mas não se ilude com a educação como fator de alavancagem do desenvolvimento. Tanto é assim que, após tal referência, ele disserta sobre as que seriam as "condições reais" do crescimento a longo prazo. De fato

"(...) é difícil saber exatamente como obter essas condições. Parece que elas podem resumir-se na existência de um governo constitucionalmente estável, capaz de garantir uma política macroeconômica razoável, com uma moeda relativamente forte e que liberte a economia de regulamentação que impeça o pleno funcionamento dos mercados. (...) As políticas que produzem o crescimento podem ser identificadas, portanto, como aquelas que geram a estabilidade macroeconômica e a eficiência microeconômica e abrem a economia para o comércio internacional."

Ao que parece, muito se terá que esperar, até que as políticas do desenvolvimento econômico venham a ser as do desenvolvimento do sistema de qualificaçäo da força de trabalho.

De fato, nada tem sido mais idealizado que a técnica e o sistema educacional, científico e tecnológico que a configura: voltados a qualificar máquina ou homem. Arrancados de sua própria realidade econômica, perversa, paradoxalmente, eles têm servido de estuário das esperanças de redenção das iniquidades que reinam entre nações, regi- 
ões e classes sociais. Idealização que, como bastando a si própria, converte a técnica na via mais eficaz que a humanidade disporia para ser alçada ao reino do bem-estar. Induz-se, assim, que, se é pela via da revolução técnica, então não seria pela da revolução social, que, transformando as atuais relações de distribuição, as desigualdades poderiam vir a ser superadas. Por isso, contrapondo-se à transformação das relações de distribuição da renda, a técnica é tida, no ideal conservador, como a via mais eficaz de acesso das nações ao bem estar-social.

Porém os vôos das utopias são curtos. Contra eles, fala a própria realidade da técnica em suas múltiplas manifestações. $E$ a realidade mostra teimosamente que a técnica não se tem prestado a reduzir. mas a amplificar concentração de renda, desequilíbrios econômicos e desigualdades sociais, nacionais ou internacionais: perversidades contra as quais ela é apresentada insistentemente, como antídoto eficaz. Com isso, conservadas as atuais relações de propriedade, produção e distribuição da riqueza, se voltada para qualificar o homem, como geradora de desenvolvimento, a técnica não é levada a sério. E se voltada para a máquina, não se presta à "homogeneização social". Impasse que tem convertido a técnica em coveira das ilusões de redenção social nela ainda depositadas.

\section{NOVOS IDEAIS}

Avoluma-se o discurso político sugerindo novos caminhos de retomada do desenvolvimento, agora, associados aos do sistema educacional, científico e tecnológico. Chama-se a atenção para a força da alavancagem do desenvolvimento econômico eqüitativo que tal sistema teria, se voltado a qualificar, prioritariamente, não mais a máquina, mas o homem. No entanto, tal discurso não se tem mostrado convincente. Nem novo. $\mathrm{Na}$ verdade, ele apenas recicla os ideais humanistas da técnica, reciclando, também, os ideais das relações Capital-Estado, cooperativas, ainda em profunda crise. Relações de sustentação estatal ou social da acumulação privado- capitalista, não mais na forma direta, via estatização de funções produtivas (monetárias, produtivas propriamente e comerciais), senão indireta, via estatização das chamadas funções sociais. 
No novo ideário, não mais seria prioridade nacional o financiamento gratuito da expansão da infra-estrutura econômica - produtiva, comercial ou financeira - senão da social: educacional, científica e tecnológica. Nem a estatização de fábricas de aço, energia ou plástico, subsidiando a rentabilidade da produção. Nem a estatização do mercado financeiro, subsidiando a rentabilidade da especulação. Prioridade passaria a ser a expansão do sistema educacional, científico e tecnológico, numa forma que viesse a servir a educação ou a qualificação técnica da força de trabalho. Assim, ao que parece, nesse novo ideário, a técnica desembarcaria decididamente da máquina, do capital ou do privado, do "hardware", para embarcar no homem, no trabalho ou no social, no "software".

Não obstante, mais além dessa utópica reorientação do progresso técnico, e numa subsequente redução das desigualdades nacionais, regionais ou sociais, encontra-se o real: não apenas os sólidos laços da técnica com a máquina (capital), mas também a persistente reprodução ampliada das desigualdades econômicas nos países desenvolvidos, e, mais ainda, nos subdesenvolvidos. E, nos desenvolvidos, além de estender tal reprodução em escala mundial, o progresso técnico substantivou-se no desenvolvimento do chamado "complexo industrialtecnológico-militar": máquina de guerra que, desde cedo, não permitiu o florescimento de qualquer imaginário humanista razoável fundado na técnica. Como se nẩo fosse pouco, a insistência com as usinas nucleares, apesar do seu uso pacífico, fez com que os restos de aura do progresso técnico viessem a ser banidos da população nos países desenvolvidos. Em definitivo, aí, há muito, a técnica deixou de ser substância de idealizações. É o que nunca deixou de ser: instrumento de alavancagem de supremacia tecnológica na concorrência capitalista, de concentração de renda e de poder bélico. Vias pelas quais os lucros se multiplicam.

Nos paises subdesenvolvidos, porém, as idealizações em torno das magias da técnica proliferaram, sobretudo porque nos países industrializados, seu desenvolvimento era real, enquanto, nos subdesenvolvidos, a indústria permanecia como ilusão. Ilustra tal credo a revisão das propostas econômico-desenvolvimentistas que Celso Furta- 
do, príncipe cepalino, fez aparecer em "Brasil: A Construção Interrompida"(1990):

"(...) Já lá se vão quarenta anos desde que Prebisch nos ensinou observar o capitalismo como um processo de difusão do progresso técnico, difusão irregular, comandada pelos interesses das economias criadoras de novas técnicas. Quem diz progresso técnico diz aumento de produtividade, portanto condições propícias à concentração dinâmica da renda e impulso à acumulação, vetor da difusẫo de novas técnicas"(p.37).

E sendo capitalismo progresso técnico, seu desenvolvimento deve ser visto como processo social:

"(...) em que a assimilação de novas técnicas e o conseqüente aumento de produtividade conduzem à melhoria do bem-estar de uma população com crescente homogeneização social. Esta última não se deu desde o começo da industrialização capitalista. Mas, alcançado certo nível de acumulação, ela se fez inerente ao processo de desenvolvimento" (ibidem, p.39).

Vê-se que Prebisch, Furtado \& CEPAL não só idealizaram o capitalismo, ensinando a vê-lo como um "processo de difusão do progresso técnico" (e não como uma modalidade de enriquecimento privado), mas também o progresso técnico, ensinando a ver em sua difusão mundial ou nacional a predominância de uma tendência que gerasse crescente "homogeneização social" (e não crescentes concentração da renda, desequilibrios regionais e desigualdades sociais). Por isso, muitos anos depois, tal escola reconhece que

"(..) aumentos de produtividade e assimilação de novas técnicas não conduzem à homogeneização social (...) (lastimando ainda que a) industrialização, nas condições de subdesenvolvimento, mesmo ali onde ela permitiu um forte e prolongado aumento de produtividade, (não) tenha contribuído nada ou quase nada para reduzir a heterogencidade social" (Furtado, 1990, ibidem, p. 39 e 45). 


\section{IDEAIS E REALIDADE}

Ao contrário da política desenvolvimentista, positiva, que idealiza a técnica, localizando em sua evolução caminhos que convergiriam à superação das desigualdades sociais, nacionais ou regionais, no pensamento critico, não se encontram margens para fantasias. De fato, nele, o progresso técnico foi exaustivamente apontado como arma da concorrência capitalista. E sua evolução, reconstituindo supremacias tecnológicas, produtivas e econômicas numas poucas empresas, traria consigo a concentração do capital, a monopolização dos mercados e a centralização da renda. Marx deu tanto significado ao progresso técnico, que nele visualizou a própria lei geral do desenvolvimento capitalista: centralização, polarização ou concentração de riqueza, de um lado, capitalista, e, de pobreza, miséria e penúria, de outro lado, do trabalhador.

A crítica ao progresso técnico, seu desenvolvimento sob o capitalismo, foi implacável. Porém, não à técnica propriamente. E nem mesmo às suas relações preferenciais para com a máquina ou agressivas contra o homem, força de trabalho, mas às relações capitalistas de distribuição dos seus frutos, que garantem apenas ao capitalista a apropriação das rendas adicionais geradas no seu desenvolvimento, tecnológico. Na verdade, tál dicotomia máquina - homem, a que a técnica estaria submetida, não é relevante. Pois, se incorporada à máquina (é capital constante ou "morto") ou ao homem (é capital variável ou "vivo"), ambos, na produção, são só capitais: propriedades capitalistas ou fatores de produção cujo resultado não se torna propriedade do produtor direto, o homem-trabalhador, mas do próprio proprietário das condições de trabalho o homem-capitalista. Assim, sob tais relações de distribuição, o progresso técnico, tanto quanto a elevação da produtividade do trabalho que o acompanha, em definitivo, não servem ao homem, mas ao capital. Os frutos do progresso técnico não vão para os bolsos do trabalhador, mas do capitalista, concentrando-se, ainda mais, tanto a propriedade, quanto as rendas nos bolsos capitalistas.

Nestas condições, a polarização enriquecimento privado, capitalista, e empobrecimento social, trabalhador, que a técnica amplifica, jamais viria a ser mudada, "desviando-se" a técnica da melhoria 
da qualificação da máquina para a da força de trabalho: mesmo que a técnica fosse passivel de ser reorientada para outras realidades, mais além daquelas fantasiadas. Na verdade, mantidas as atuais relações de propriedade, distribuição e enriquecimento, ainda que toda destreza técnica do mundo viesse a ser canalizada ao trabalhador, ainda assim, o trabalhador assalariado não viria a ser nem mais nem menos aquinhoado com os frutos do progresso técnico. E simplesmente porque, apesar da destreza adquirida, não sendo revertidas as atuais relações de distribuição, ele nada mais apropria da produção, senão seu próprio salário, exterminativo.

Ao contrário, tal evolução viria a ser revertida apenas sob mudança das relações capitalistas de propriedade, apropriação e acumulação da renda nacional. Nesse caso, a propriedade da produção deixa de ser "coisa privada" do empresário capitalista, proprietário da máquina (capital), para ser "coisa social" do conjunto da sociedade. Com isso, a técnica não deixa de servir à máquina, enquanto meio de produção, mas, sim, enquanto capital, deixando de servir ao proprietário da máquina para servir ao produtor, à sociedade. Em outras palavras: não é deixando de servir à máquina, para vir a servir ao homem, que os frutos do progresso técnico alcançariam ao trabalhador. Aliás, não é nem deixando de servir à máquina que o progresso técnico serviria ao homem, à sociedade: a máquina é que precisa deixar de servir ao capital, vindo a servir à sociedade. $\mathrm{E}$ isso só acontece quando ela deixa de ser propriedade privada, capital do investidor, para vir a ser propriedade social, meio de produção da própria sociedade.

Enfim, àqueles modelos que idealizam a técnica, seus "dotes curandeiros", não se contrapõe um outro modelo idealizado (tornando-o ainda mais "charmoso"), mas a própria realidade, que é, tanto história, quanto lógica. Assim, enquanto a realidade se apresenta em suas opositividades distributivas características, a lógica se apresenta apenas reproduzindo tais opositividades. E a realidade é insofismável: em seu desenvolvimento capitalista, o progresso técnico não tem sido instrumento da redução, senão da monopolização de crédito, produção e mercado, da concentração de renda e da amplificação das desigualdades econômico-sociais. 
REFERÊNCIAS BIBLIOGRAFICAS

Netto, Delfim. "Políticas Geradoras do Desenvolvimento", in Conjuntura Econômica, Rio de Janeiro, FGV, dez 1993.

Furtado, Celso. Brasil: A Construção Interrompida, Rio de Janeiro, Paz e Terra, 1990. 


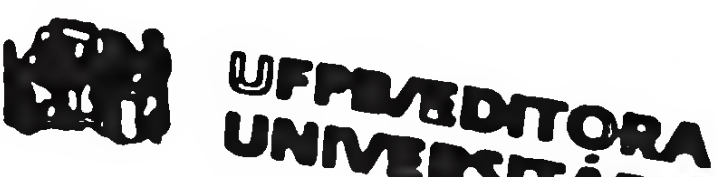

UNMESTITRAA 